\title{
High-cycle and very-high-cycle fatigue behaviour of a titanium alloy with equiaxed microstructure under different mean stresses
}

\author{
Xiangnan $\operatorname{Pan}^{1,2}$ (D) | Youshi Hong ${ }^{1,2}$ (D)
}

${ }^{1}$ State Key Laboratory of Nonlinear Mechanics, Institute of Mechanics, Chinese Academy of Sciences, Beijing, China

${ }^{2}$ School of Engineering Science, University of Chinese Academy of Sciences, Beijing, China

\section{Correspondence}

Y. Hong, State Key Laboratory of Nonlinear Mechanics, Institute of Mechanics, Chinese Academy of Sciences, Beijing 100190, China.

Email: hongys@imech.ac.cn

\section{Funding information}

Strategic Priority Research Program of the Chinese Academy of Sciences, Grant/ Award Numbers: XDB22020201 and XDB22040503; National Natural Science Foundation of China, Grant/Award Number: 11572325

\begin{abstract}
The fatigue behaviour of a titanium alloy Ti-6Al-4V with equiaxed microstructure (EM) under different values of tensile mean stress or stress ratio $(R)$ was investigated from high-cycle fatigue (HCF) to very-high-cycle fatigue (VHCF) regimes via ultrasonic axial cycling. The effect of mean stress or $R$ on the fatigue strength of HCF and VHCF was addressed by Goodman, Gerber, and Authors' formula. Three types of crack initiation, namely, surface-with-RA (rough area), surface-without-RA, and interior-with-RA, were classified. The maximum value of stress intensity factor (SIF) at RA boundary for $R<0$ keeps constant regardless of $R$ in HCF and VHCF regimes. The SIF range at RA boundary for $R>0$ also keeps constant regardless of $R$ in VHCF regime, but this value decreases linearly with the increase of $R$ for surface RA cases. The microstructure observation at RA regions gives a new result of nanograin formation only in the cases of negative stress ratios for the titanium alloy with EM, which is explained by the mechanism of numerous cyclic pressing.
\end{abstract}

\section{KEYWORDS}

fatigue crack initiation, mean stress, stress ratio, titanium alloy, very-high-cycle fatigue

\section{1 | INTRODUCTION}

Because of high tensile strength to density ratio and high corrosion resistance, titanium alloys have been widely used in many engineering applications, such as airplanes, marine structures, transportation vehicles, and medical tools. Fatigue failure is one of the most common types of destruction in engineering materials and structures, ${ }^{1}$ and very-high-cycle fatigue (VHCF), which is fatigue failure beyond $10^{7}$ cycles, has become a major research issue in fatigue field..$^{2-9}$ For titanium alloys, the behaviour of high-cycle fatigue $(\mathrm{HCF})^{10-12}$ and $\mathrm{VHCF}^{13-20}$ has drawn more and more attention.

The fatigue behaviour of metallic materials is evidently affected by the extent of applied mean stress $\left(\sigma_{\mathrm{m}}\right)$ or stress ratio $(R)$, which was early analysed by Gerber $^{21}$ and

\footnotetext{
Nomenclature: BF, bright filed; BM, bimodal microstructure; EM, equiaxed microstructure; FCG, fatigue crack growth; FGA, fine granular area; FIB, focused ion beam; FiE, fish-eye; HCF, high-cycle fatigue; int, specimen interior; Int-RA, crack initiated at int to form an internal RA region; LM, lamellar microstructure; NCP, numerous cyclic pressing; NG, nanograin; Pt, platinum protection layer; RA, rough area; SAD, selected area diffraction; SEM, scanning electron microscope; SIF, stress intensity factor; Sub-RA, crack initiated at subsurface to form a surface RA region; sur, specimen surface; Sur-RA, crack initiated at sur to form a surface RA region; TEM, transmission electron microscopy; UTS, ultimate tensile strength; VHCF, very-high-cycle fatigue; $\sqrt{\operatorname{area}_{\mathrm{RA}}}$, square root of RA projection area; $d_{\mathrm{RA}}$, distance between RA centre and sur; $K$, SIF; $K_{\mathrm{max}}$, maximum value of SIF; $\Delta K$, range of SIF; $N$, number of cycles to failure; $R$, stress ratio; $V_{\text {equi }} \alpha$, volume fraction of equiaxed $\alpha$ grains; $\delta$, uniform elongation; $\sigma_{\mathrm{a}}$, stress amplitude; $\sigma_{\mathrm{m}}$, mean stress; $\sigma_{\max }$, maximum stress; $\sigma_{\mathrm{u}}$, UTS; $\sigma_{\mathrm{y}}$, yield strength.
} 
Goodman. ${ }^{22}$ As a typical case, Sakai et al ${ }^{23}$ investigated the VHCF behaviour of a bearing steel with axial cyclic loading and proposed a bilinear model to address the mean stress effect with an intersect point at $R=0.5$ in the related Haigh diagram. Recently, Huang et $\mathrm{al}^{24}$ showed that this model was able to describe the fatigue strength up to $10^{9}$ cycles under different mean stresses for a titanium alloy with bimodal microstructure (BM). The state of $\sigma_{\mathrm{m}}$ or $R$ also affects fatigue failure type, in which the cleavage facets from $\alpha$ grains were regarded as crack origins for titanium alloys under cyclic loading. ${ }^{10}$ In an example of a titanium alloy with BM, the failure type of surface-without-facets was observed at negative $R$ cases, and the types of surface-with-facets or interiorwith-facets prevailed at positive $R$ cases. ${ }^{25-27}$ Furuya and Takeuchi ${ }^{28}$ also reported that Ti-6Al-4V alloy with BM was more prone to internal crack initiation under tensile mean stress conditions, leading to reduced fatigue strength. In addition, Nikitin et $\mathrm{al}^{29}$ demonstrated that for the case of fatigue testing with tensile mean stress for a forged titanium alloy with lamellar microstructure (LM), internal crack initiation was induced by microstructure inhomogeneities.

For most titanium alloys, equiaxed microstructure (EM), BM, LM, and basket weave microstructure are four typical microstructures. The volume fraction of equiaxed $\alpha$ grains $\left(\right.$ Vol $\left._{\text {equi } \alpha}\right)$ determines the type of EM or BM, and the equiaxed $\alpha$ grain is the potential defect to cause fatigue crack initiation due to its brittleness. Note that the available results in the literature were almost with regard to the titanium alloys with $\mathrm{BM}\left(\mathrm{Vol}_{\text {equi } \alpha}<30 \%\right)$, and the effects of $\sigma_{\mathrm{m}}$ or $R$ on VHCF behaviour for the titanium alloys with EM ( $V o l_{\text {equi } \alpha}>75 \%$ as in this paper) are still rarely reported, although EM is very common for titanium alloys. Actually, almost all commercial titanium alloys are EM type, which are less expensive, whereas the titanium alloys with BM microstructure are used in some special applications, for which relevant heat treatment is necessary to obtain the required microstructure.

For the VHCF failures of high-strength steels and titanium alloys, more than $95 \%$ of fatigue life is consumed by the process of crack initiation. ${ }^{30,31}$ The morphology of internal crack initiation is the so called fish-eye (FiE) mode, which is the typical fractographic feature for VHCF. ${ }^{6,16,17,30,31}$ Inside the FiE region, a rough area always presents, which is named fine granular area (FGA) in high-strength steels ${ }^{32}$ and rough area (RA) in titanium alloys. ${ }^{31}$ The maximum value of stress intensity factor (SIF) $K_{\max }$ at the periphery of FGA region is close to the threshold value for fatigue crack growth (FCG). ${ }^{33,34}$ The similar results demonstrate that the effective value of SIF at the boundary of RA region corresponds to the FCG threshold in vacuum for titanium alloys with BM. ${ }^{25,31}$ Previous investigations ${ }^{6,30,31}$ have indicated that FGA or RA is the characteristic region of internal crack initiation for VHCF. It has been revealed that the nature of FGA in high-strength steels is a nanograin layer, and the model of numerous cyclic pressing (NCP) has been proposed to explain the formation mechanism of FGA. ${ }^{35}$ The NCP model is proved valid for titanium alloys ${ }^{31,36}$ and is supported by the results of numerical simulations. ${ }^{37}$

It is noteworthy that in the VHCF process of titanium alloys with EM under $R=-1$, the crack initiation site is always at the specimen surface. As the value of $R$ increases, the VHCF failure of some specimens is originated from internal crack initiation, and the fatigue failure of the others is still induced by surface crack initiation. ${ }^{36}$ For the VHCF of a titanium alloy with EM, three types of fatigue failure, ie, surface-without-RA, surface-with-RA, and interior-with-RA, were categorized, and the examinations suggested that the vacuum-like environment is not the essential condition for the formation of nanograin layer in crack initiation region of $\mathrm{VHCF}^{36}$ Nevertheless, the study of surface crack initiation leading to VHCF of the titanium alloys with EM is still rare.

The threshold behaviour of FCG plays a key role in VHCF damage, which is closely related to crack initiation. Stanzl-Tschegg and Schönbauer ${ }^{38}$ investigated the near-threshold behaviour of FCG in a high-strength steel under different stress ratios in vacuum and in air. Their results were analogized to give the very low crack growth rate in FGA region. Very recently, the crack growth rate at FGA region for a high-strength steel was directly measured, ${ }^{39}$ and the results connected well with the values in the region outside FGA. ${ }^{40,41}$ In addition, previous studies ${ }^{42-44}$ demonstrated that with the increase of $R$ under air environment, the threshold value of FCG in titanium alloys was significantly reduced. Obviously, the state of $R$ will have a substantial influence on the crack initiation behaviour of VHCF for titanium alloys.

In this paper, a titanium alloy (Ti-6Al-4V) with EM was used for the investigation of the HCF and VHCF behaviour under different mean stresses via ultrasonic axial cycling. The S-N data as well as the Haigh diagrams were presented to illustrate the effects of mean stress or stress ratio on fatigue resistance. The fatigue failure types of surface-without-RA, surface-with-RA, and interior-with-RA were identified based on scanning electron microscope (SEM) observations. The morphologies of RA were carefully examined, and the values of RA size and its distribution were measured. The values of SIF at the periphery of RA regions were calculated, and the threshold behaviour of FCG in relation to RA regions was discussed. The samples for microstructure characterization of the RA regions were prepared by focused ion 
beam (FIB) technique and examined by transmission electron microscopy (TEM). The selected area diffraction (SAD) patterns show that nanograin formation only occurred underneath the RA regions in VHCF at $R=-1$. It is clarified again that the NCP mechanism dominates the microstructure evolution of the characteristic region of crack initiation, ie, RA region, in the titanium alloy with EM.

\section{2 | TESTED MATERIAL AND METHODS}

\section{1 | Tested material}

The material investigated in this paper is an $\alpha+\beta$ titanium alloy $\mathrm{Ti}-6 \mathrm{Al}-4 \mathrm{~V}$, with the chemical composition (wt.\%) of $5.96 \mathrm{Al}, 4.13 \mathrm{~V}, 0.16 \mathrm{Fe}, 0.02 \mathrm{C}, 0.015 \mathrm{~N}, 0.0036$ $\mathrm{H}, 0.18 \mathrm{O}$, and balance Ti. The microstructure of the tested material is shown in Figure 1A, which was observed via an SEM (FEI Quanta 200 FEG) on the cross section of the sample that was cut from the received round bar and subsequently carefully ground, polished, and etched. It is seen from Figure 1A that the tested titanium alloy has the EM consisting of the equiaxed primary $\alpha$ grains with equivalent size of about $3 \mu \mathrm{m}$ and the randomly distributed $\beta$ domains containing $\alpha+\beta$ precipitates. The $\alpha$ phase possesses about $90 \%$ volume fraction ( $\alpha$ grains of about $75 \%$ fraction plus $\alpha$ precipitates of about $15 \%$ fraction in $\beta$ domains). The tensile curves of the tested material are presented in Figure 1B from three cylindrical specimens (dog-bone shape) $10 \mathrm{~mm}$ in diameter and $56 \mathrm{~mm}$ in length for the gage section, in which the longitudinal direction is parallel to the axis of the received round bar and the strain rate is $10^{-4} \mathrm{~s}^{-1}$. The tensile test gives the results of yield strength $\sigma_{\mathrm{y}}=900 \mathrm{MPa}$, ultimate tensile strength (UTS) $\sigma_{\mathrm{u}}=980 \mathrm{MPa}$, and uniform elongation $\delta=8.25 \%$.

\section{2 | Experimental methods}

An ultrasonic fatigue testing facility (Lasur GF20-KT) as shown in Figure 2A was used to perform the fatigue tests of the tested titanium alloy at room temperature, in air, and with a resonant frequency of $f=20 \mathrm{k} \pm 500 \mathrm{~Hz}$. The facility provides an ultrasonic axial cycling superimposed by a quasi-static axial tension to the specimen, and this is achieved by the piezoelectric vibration system mounted on an electromechanical tensile machine. Before fatigue testing, the output amplitude from the transducer of the ultrasonic machine was calibrated by a specific device to ensure the correctness of the output data from the transducer. During fatigue testing, the displacement amplitude keeps constant (with respect to a given input value) via the transducer together with the control system of the ultrasonic machine. Thus, this constant vibration amplitude can be converted to the strain amplitude of the specimen by the known vibration equation, and eventually the stress amplitude can be obtained by the constitutive relation of the tested titanium alloy.

The ultrasonic specimens were machined from the received round bars (16 $\mathrm{mm}$ in diameter) into an hourglass shape with a reduced section of $3.5 \mathrm{~mm}$ in diameter. The specimen design and installation are illustrated in Figure 2B, and the installed specimen satisfies the resonant frequency condition. ${ }^{45}$ The specimen was connected to the upper and the lower horn with its end screws $(\mathrm{M} 5 \times 0.8)$. Note that for the testing cases of $\sigma_{\mathrm{m}}=0$ or $R=-1$, the specimen lower end is free.

Fatigue tests were carried out under different values of mean stress $\left(\sigma_{\mathrm{m}}=0\right.$, or between 166 and $\left.884 \mathrm{MPa}\right)$ in $\mathrm{HCF}$ and VHCF regimes, in which the range of loading cycles is between $10^{5}$ and $2 \times 10^{9}$. In terms of $R$, the full reversed tension-compression $(R=-1)$ fatigue is evolved to an asymmetrical tension-compression type
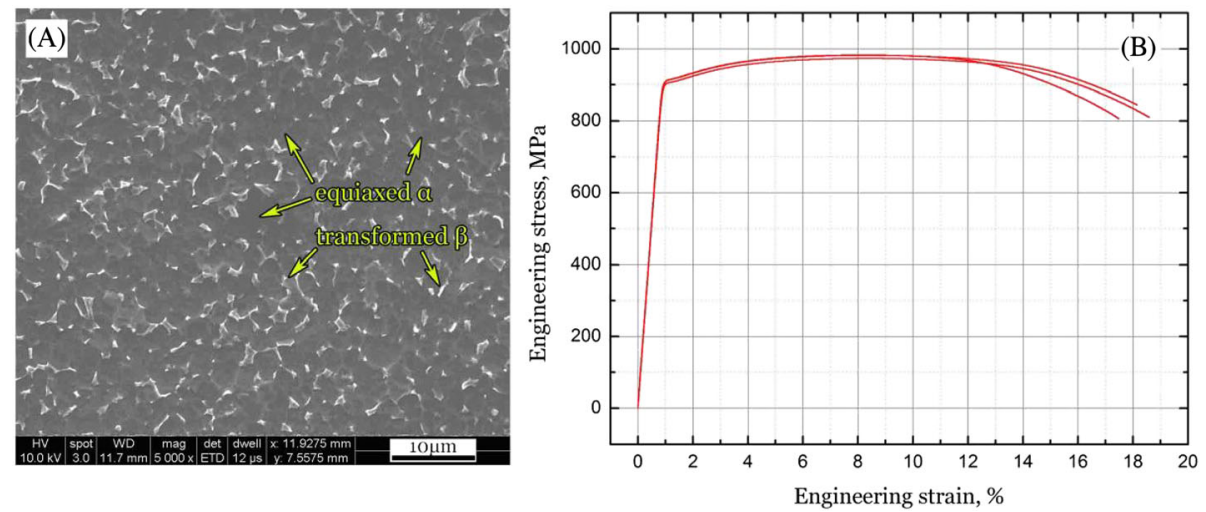

FIGURE 1 Microstructure and tensile properties of tested material: A, A scanning electron microscope (SEM) image showing equiaxed microstructure (EM); B, tensile stress-strain curves of three specimens [Colour figure can be viewed at wileyonlinelibrary.com] 


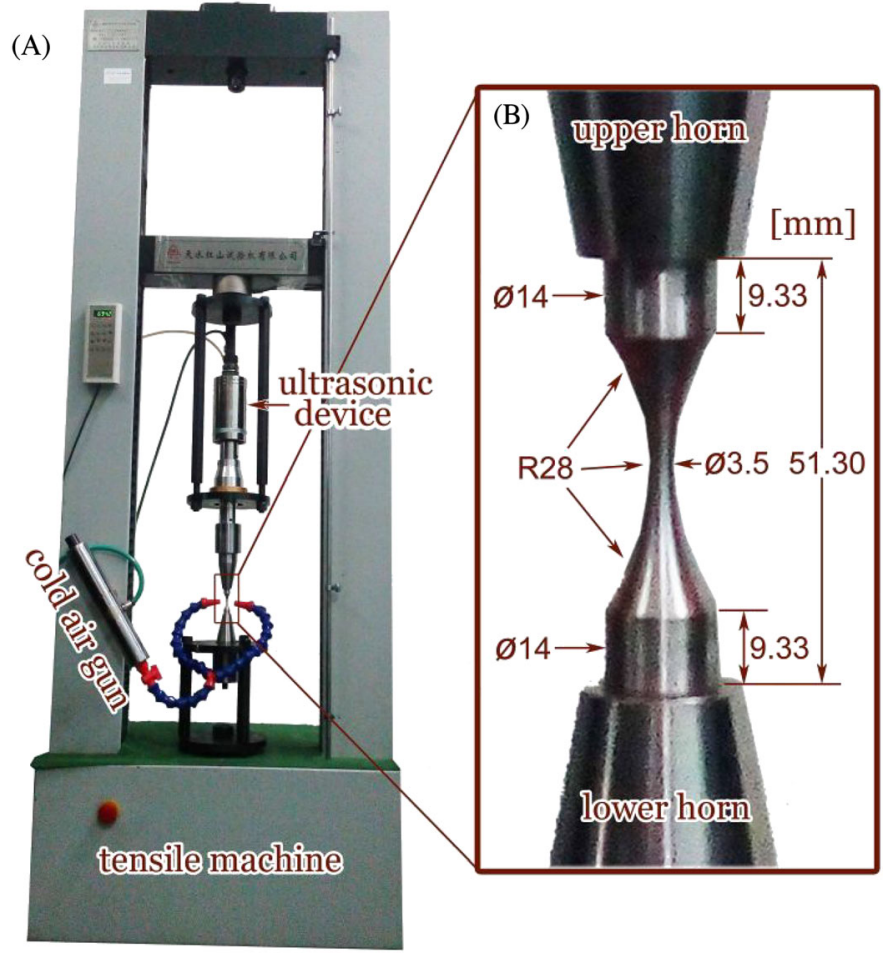

FIGURE 2 A, Ultrasonic fatigue testing facility (Lasur GF20-KT) mounted in a tensile machine; $\mathrm{B}$, specimen geometry and its installation [Colour figure can be viewed at wileyonlinelibrary.com] (about $R=-0.3)$, then a pulsating cycling $(R=0)$, and, lastly, a tension-tension fatigue $(0<R \leq 0.8)$. The specimens were cooled by compressed cold air as also shown in Figure 2A during fatigue tests. There was no noticeable temperature rise during fatigue testing to affect the $\mathrm{HCF}$ and VHCF behaviour of the tested titanium alloy.

After fatigue testing, the fracture surfaces of failed specimens were carefully observed by using an SEM (JEOL JSM-IT300). The failure types and the crack origination sites of RA regions were identified on the fracture surfaces. The morphologies of crack initiation and growth were examined in the RA regions and in the regions outside RA. The values of RA size and its distribution were accordingly measured by using the software of Image-Pro Plus 6.0.

The profile samples from the selected RA regions were prepared by FIB milling with a dual beam (FIB-SEM) system FEI Helios Nanolab 600i. First, a platinum layer (Pt) was deposited on the top of the selected position to protect the fracture surface from the damage during FIB processing. Then, the sample (length, $10 \mu \mathrm{m}$; width, $5 \mu \mathrm{m}$; and thickness, $50 \mathrm{~nm}$ ) was cut along the longitudinal section of the RA region and lifted out to be mounted on a molybdenum grid. Finally, the FIB sample was further polished to a thin membrane with the thickness about $50 \mathrm{~nm}$. Such FIB samples were carefully examined by TEM (FEI Tecnai G2 F30 S-Twin), and the observations were demonstrated by bright filed (BF) images with SAD patterns in which the diameter of the detected area was $200 \mathrm{~nm}$.

\section{3 | RESULTS AND DISCUSSION}

In this part, first, the S-N data and the resulting Haigh diagrams with relevant discussion are presented in Section 3.1 to show the effect of mean stress or stress ratio on $\mathrm{HCF}$ and VHCF performance of the tested titanium alloy. Consequently, the overall fractography and the RA morphology with regard to crack initiation are described in Section 3.2. Then, the results with the analyses on the values of $K_{\max }$ and $\Delta K$ for RA regions are given in Section 3.3. Finally, the characterizations of microstructure feature for RA regions are demonstrated in Section 3.4. Note that from Sections 3.2 to 3.4, the propensity of crack initiation is focused and discussed in depth.

\section{1 | Fatigue resistance}

Figure $3 \mathrm{~A}$ shows the obtained S-N data, presenting the stress amplitude $\sigma_{\mathrm{a}}$ as a function of fatigue life $N_{\mathrm{f}}$ of the tested titanium alloy under axial cycling with different mean stresses $\left(\sigma_{\mathrm{m}}=0,166,208,220,312,447,468,520\right.$, $625,728,786,832$, and $884 \mathrm{MPa})$. For the case of $\sigma_{\mathrm{m}}=0$, ie, $R=-1$, the range of $\sigma_{\mathrm{a}}$ in HCF and VHCF regimes is between 400 and $550 \mathrm{MPa}$ as shown by the black dashed lines in Figure 3A. When $\sigma_{\mathrm{m}}$ is between 166 and $312 \mathrm{MPa}$, the fatigue resistance in VHCF regime exhibits a large scattering with the value of $\sigma_{\mathrm{a}}$ in the range between 203 and $375 \mathrm{MPa}$ as shown by the red dashed lines in Figure 3A. After that, as $\sigma_{\mathrm{m}}$ further increases, the 

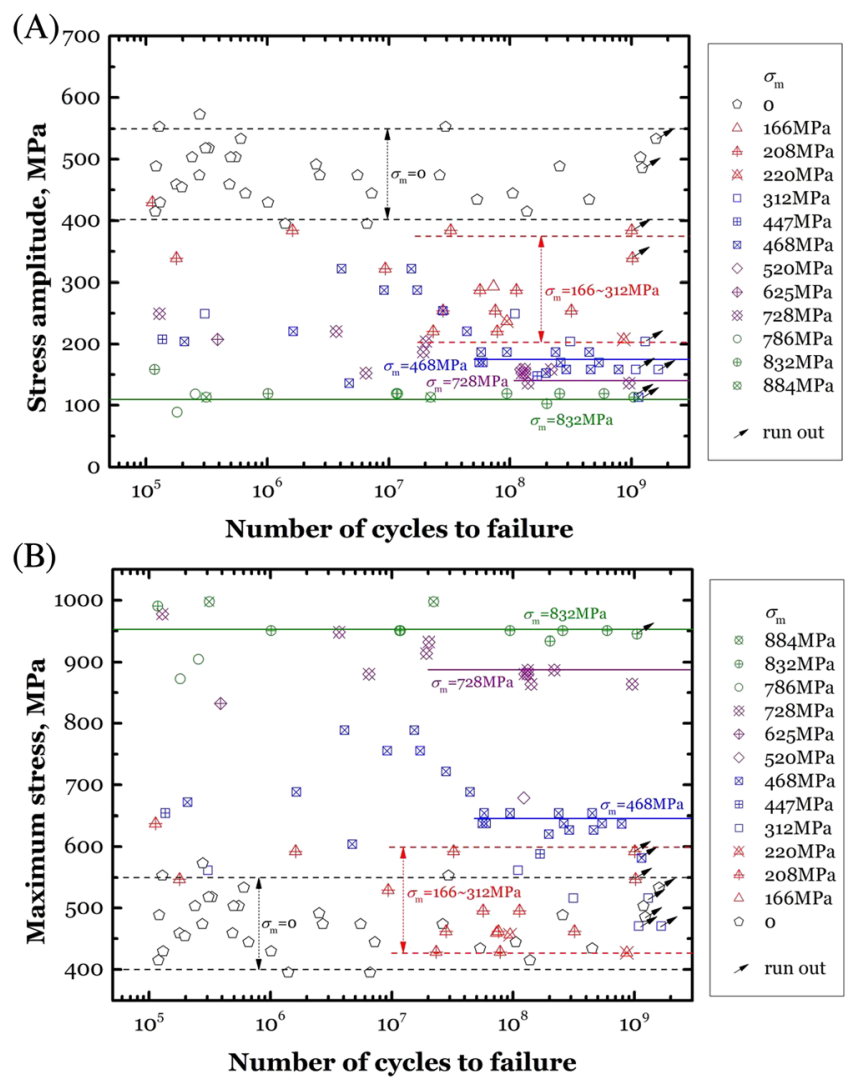

FIGURE $3 \mathrm{~S}-\mathrm{N}$ data of tested titanium alloy under different values of $\sigma_{\mathrm{m}}(\mathrm{A})$ in terms of $\sigma_{\mathrm{a}}$ and (B) in terms of $\sigma_{\max }$ [Colour figure can be viewed at wileyonlinelibrary.com]

decrement in the fatigue resistance is less substantial. For instance, while the value of $\sigma_{\mathrm{m}}$ increases to $468(R=0.5)$, $728(R=0.7)$, and $832 \mathrm{MPa}(R=0.8)$, the resistance decreases to about 176,140 , and $111 \mathrm{MPa}$, respectively, as shown by the blue, purple, and olive solid lines in Figure 3A.

The $\mathrm{S}-\mathrm{N}$ data are also presented in Figure 3B showing the maximum stress $\sigma_{\max }$ as a function of the number of cycles to failure. Obviously, the VHCF resistance of the tested titanium alloy in terms of $\sigma_{\max }$ has the same range between 400 and $550 \mathrm{MPa}$ as the resistance in terms of $\sigma_{\mathrm{a}}$ under $\sigma_{\mathrm{m}}=0$ or $R=-1$, as shown by the two black dashed lines in Figure 3B. When $\sigma_{\mathrm{m}}$ increases to the range between 166 and $312 \mathrm{MPa}$, the test data slightly shift up to the range between 428 and $600 \mathrm{MPa}$ as shown by the red dashed lines. After that, when $\sigma_{\mathrm{m}}$ increases to $468(R=0.5), 728(R=0.7)$, and $832 \mathrm{MPa}(R=0.8)$, the resistance increases to about 644, 868, and $943 \mathrm{MPa}$, respectively, as shown by the blue, purple, and olive solid lines in Figure 3B.

By the comparison of Figure 3A with Figure 3B, it is seen that the VHCF resistance in terms of $\sigma_{\mathrm{a}}$ is more sensitive to the cases of $\sigma_{\mathrm{m}} \leq 312 \mathrm{MPa}$, and the VHCF resistance in terms of $\sigma_{\max }$ is sensitive to the cases of $\sigma_{\mathrm{m}}$ between 468 and $728 \mathrm{MPa}$. This implies that there exists a minimum value of the resistance in terms of $\sigma_{\mathrm{a}}$ for which the resistance is less sensitive to the increase of $\sigma_{\mathrm{m}}$ for the tested titanium alloy, whereas for the resistance in terms of $\sigma_{\max }$, there exists a range of $\sigma_{\mathrm{m}}$, outside of which the resistance is insensitive to $\sigma_{\mathrm{m}}$.

The Haigh diagram ${ }^{46}$ was used to express the effects of $\sigma_{\mathrm{m}}$ or $R$ on the fatigue behaviour of the tested titanium alloy. For the purpose of constructing the Haigh diagrams, the Goodman formula ${ }^{22}$, Gerber formula, ${ }^{21}$ and the authors' previously proposed formula ${ }^{36}$ are adopted:

$$
\begin{aligned}
& \text { Goodman formula: } \frac{\sigma_{\mathrm{a}}}{\sigma_{-1}}=1-\frac{\sigma_{\mathrm{m}}}{\sigma_{\mathrm{u}}}, \\
& \text { Gerber formula: } \frac{\sigma_{\mathrm{a}}}{\sigma_{-1}}=1-\left(\frac{\sigma_{\mathrm{m}}}{\sigma_{\mathrm{u}}}\right)^{2}, \\
& \text { Authors' formula: } \frac{\sigma_{\mathrm{a}}}{\sigma_{-1}}=\left(1-\frac{\sigma_{\mathrm{m}}}{\sigma_{\mathrm{u}}}\right)^{2},
\end{aligned}
$$

where $\sigma_{-1}$ is the fatigue strength under $R=-1$ or $\sigma_{\mathrm{m}}=0$ and $\sigma_{\mathrm{u}}$ is the UTS (980 MPa) of the tested titanium alloy.

Figure 4A-C shows the Haigh diagrams of the present data showing the fatigue resistance in relation to $\sigma_{\mathrm{a}}$ and $\sigma_{\mathrm{m}}$. Figure $4 \mathrm{~A}$ is the case of $N_{\mathrm{f}}$ at $10^{6}$ cycles, in which the test data within the HCF range between $10^{5}$ and $10^{7}$ failure cycles are plotted. In Figure $4 \mathrm{~A}, \sigma_{-1}$ is taken as $500 \mathrm{MPa}$, which is the average value of the data in the failure range between $10^{5}$ and $10^{7}$ cycles at $R=-1$. Figure $4 \mathrm{~B}$ is the case of $N_{\mathrm{f}}$ at $10^{7}$ cycles, and the test data within the range of $N_{\mathrm{f}}$ between $10^{6}$ and $10^{8}$ cycles are plotted. In Figure $4 \mathrm{~B}, \sigma_{-1}$ is taken as $450 \mathrm{MPa}$, which is the average value of the data in the failure range between $10^{6}$ and $10^{8}$ cycles at $R=-1$. Figure $4 \mathrm{C}$ is the case of $N_{\mathrm{f}}$ at $10^{9}$ cycles, and the test data with the $N_{\mathrm{f}}$ greater than $10^{8}$ are plotted in this figure. In Figure $4 \mathrm{C}$, $\sigma_{-1}$ is taken as $450 \mathrm{MPa}$, which is the average value of the data of the specimens failed between $10^{8}$ and $10^{9}$ cycles as well as the specimens runout at $10^{9}$ cycles at $R=-1$. Thus, Figure $4 \mathrm{~A}$ describes the effect of $\sigma_{\mathrm{a}}$ and $\sigma_{\mathrm{m}}$ in HCF regime, Figure 4B demonstrates this effect with respect to the traditional fatigue limit, and Figure 4C presents this effect in VHCF regime.

For the case of HCF regime (Figure 4A), the solid points failed between $10^{5}$ and $10^{6}$ cycles, and the hollow points failed between $10^{6}$ and $10^{7}$ cycles. At the fatigue life of $10^{6}$ cycles, there is a large scattering for the test data along the dot lines of $R=-1$ and $R=0.5$. In general, Goodman line has a relatively good fit with the test data, Gerber curve is less conservative, and authors' curve is conservative for this case. 

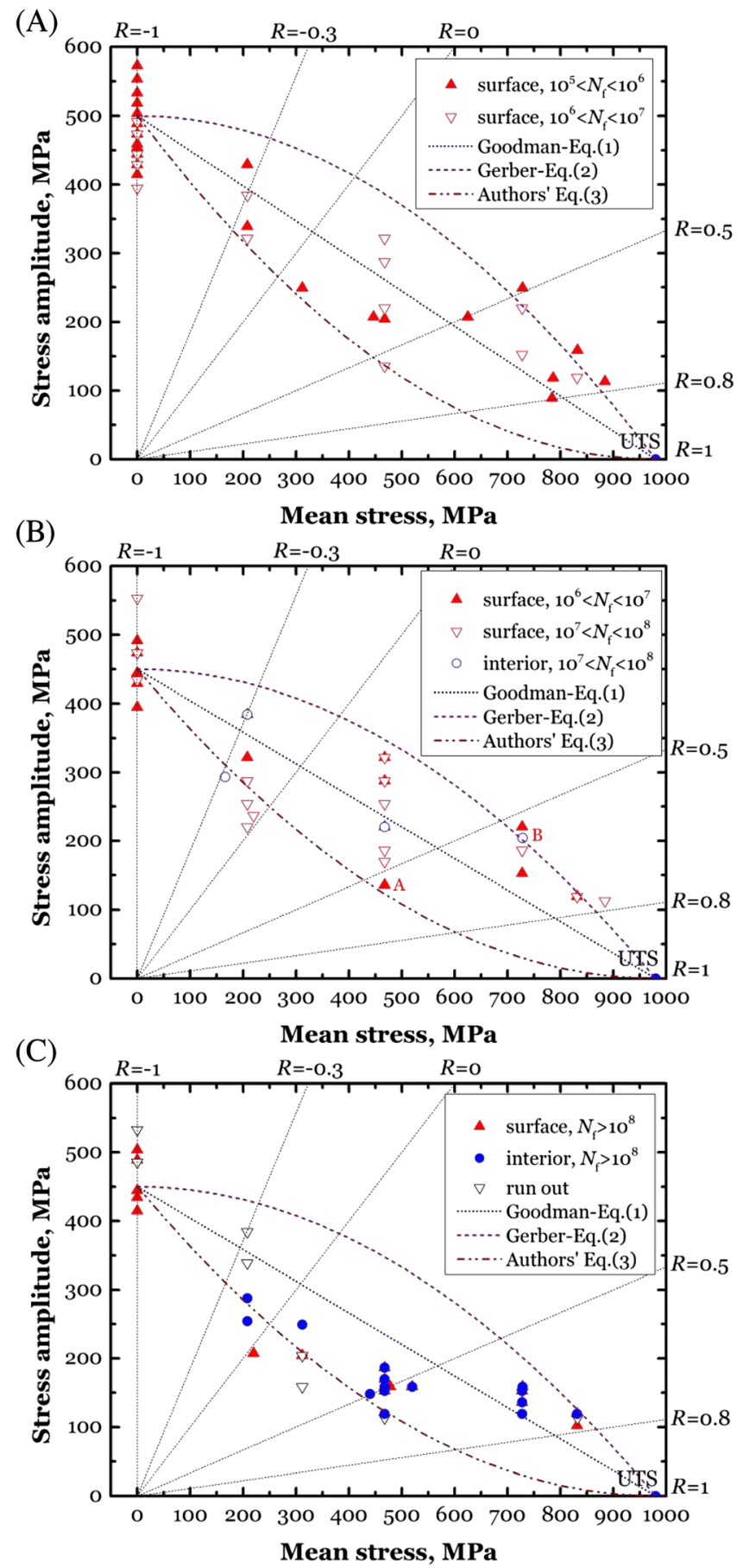

FIGURE 4 Haigh diagrams showing fatigue data in relation to $\sigma_{\mathrm{a}}$ and $\sigma_{\mathrm{m}}(\mathrm{A})$ for high-cycle fatigue (HCF) regime (set case, $N_{\mathrm{f}}=10^{6}$; test data, $10^{5}<N_{\mathrm{f}}<10^{7}$ ), (B) for traditional endurance limit (set case, $N_{\mathrm{f}}=10^{7}$; test data, $10^{6}<N_{\mathrm{f}}<10^{8}$ ), and (C) for very-high-cycle fatigue (VHCF) regime (set case, $N_{\mathrm{f}}=10^{9}$; test data, $N_{\mathrm{f}}>10^{8}$ )

[Colour figure can be viewed at wileyonlinelibrary.com]

For the case of traditional endurance limit (Figure 4B), the solid points failed between $10^{6}$ and $10^{7}$ cycles, and the hollow points failed between $10^{7}$ and $10^{8}$ cycles. At $N_{\mathrm{f}}=10^{7}$, there is still a large scattering for the test data along the dot lines of $R=-1$ and $R=0.5$. In general, the same as the case of HCF regime, Goodman line has a relatively good fit with the test data, Gerber curve is less conservative, and authors' curve is conservative. It is noted that a large scattering occurred at $R=0.5$ with point A failed at $R=0.55, \sigma_{\mathrm{m}}=468 \mathrm{MPa}, \sigma_{\mathrm{a}}=136 \mathrm{MPa}$, and $N_{\mathrm{f}}=4.71 \times 10^{6}$, and point B failed at $R=0.56$, $\sigma_{\mathrm{m}}=728 \mathrm{MPa}, \sigma_{\mathrm{a}}=204 \mathrm{MPa}$, and $N_{\mathrm{f}}=2.03 \times 10^{7}$, which indicates that $\sigma_{\mathrm{m}}$ may still have a significant effect on the fatigue resistance of the tested titanium alloy even under the same value of $R$ (but different values of $\sigma_{\mathrm{a}}$ ).

For the case of VHCF regime (Figure $4 \mathrm{C}$ ), the solid points failed at $N_{\mathrm{f}}$ beyond $10^{8}$ cycles, and the hollow points were runout at $10^{9}$ loading cycles. In general, authors' curve has a good fit with the test data, and Goodman line and Gerber curve are less conservative.

To sum up the results in Figure 4A-C, Gerber relation is unconservative in the description of the effect of $\sigma_{\mathrm{m}}$ on fatigue resistance, and Goodman relation and authors' formula may describe the fatigue performance in HCF and VHCF regimes under different mean stresses or stress ratios. This trend of fatigue strength is probably caused by the change of the fatigue failure type from specimen surface to the interior in VHCF regime under tensile mean stress. It is evident that the variation of fatigue resistance is dominated by both mean stress and stress ratio.

\section{2 | Overall fractography and RA morphology}

Figure 5 shows the fracture surface morphologies of the fatigue specimens failed in $\mathrm{HCF}$ and VHCF regimes of the tested titanium alloy under different mean stresses. There are six typical morphologies, namely, single-origin surface-with-RA, multi-origin surface-with-RA, surfacewithout-RA, single-origin interior-with-RA, multi-origin interior-with-RA, and mix-type of surface-with-RA and interior-with-RA, as shown in Figure 5A-F. It is evident that there is a dominating RA region to act as the main crack origin leading to the final failure of the specimen in multi-origin cases, and the RA-01 region is the dominating origin for the specimen in Figure 5B,E,F. With regard to the mix-type of Figure 5F, the dominating fatigue failure type is surface-with-RA.

In general, surface-without-RA occurs in low-cycle fatigue and is not the dominating type of crack initiation for $\mathrm{HCF}$ and VHCF, which will be less discussed in this paper. Surface-with-RA occurs in HCF and VHCF, and interior-with-RA occurs in VHCF. The failure types of surface-with-RA and surface-withoutRA are all surface crack-induced failure, and the failure type of interior-with-RA is internal crack-induced failure. In the following descriptions, the types of 

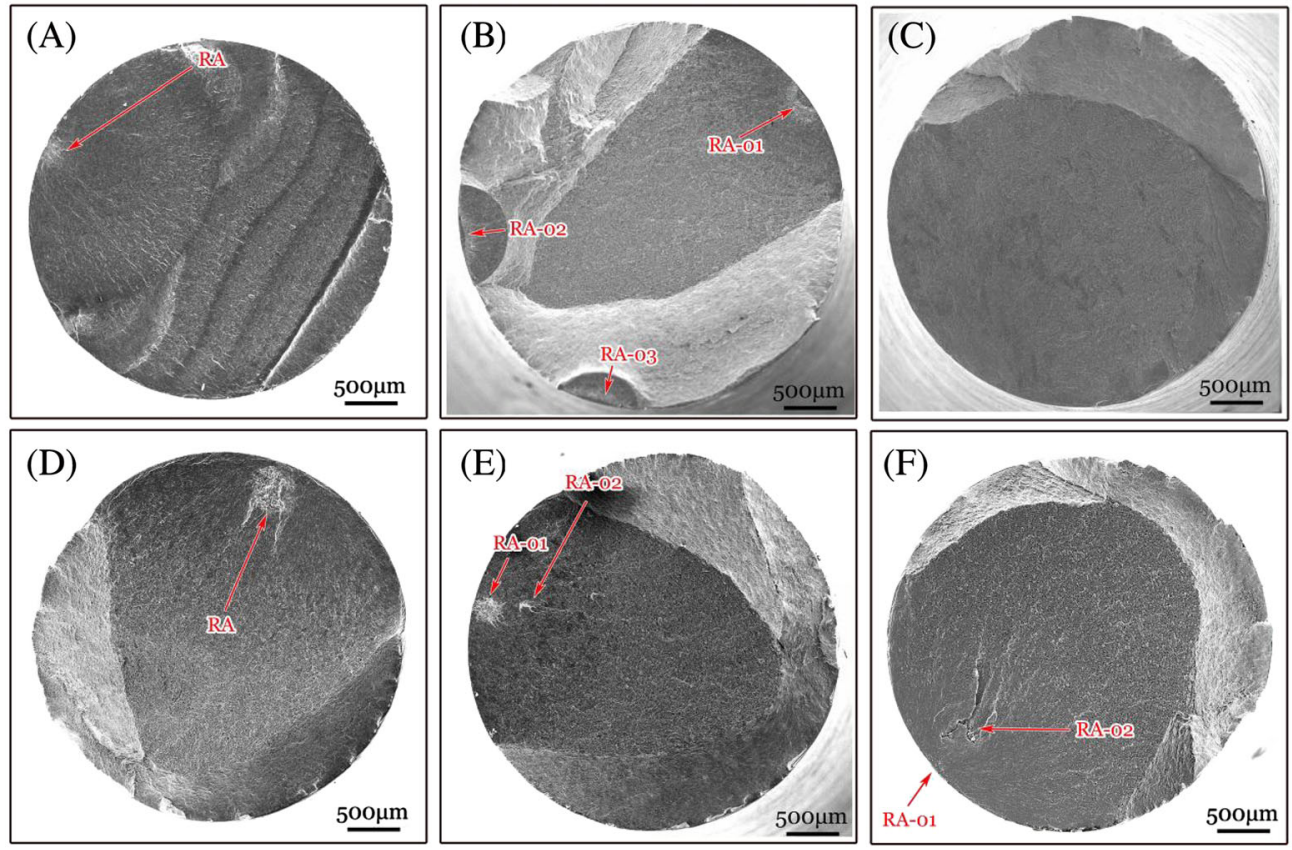

FIGURE 5 Typical fracture surface morphologies of failed specimens: (A) Single-origin surface-with-RA, $R=-1, \sigma_{\mathrm{m}}=0, \sigma_{\mathrm{a}}=533 \mathrm{MPa}$, and $N_{\mathrm{f}}=6.04 \times 10^{5}$; (B) multi-origin surface-with-RA, $R=0.8, \sigma_{\mathrm{m}}=784 \mathrm{MPa}, \sigma_{\mathrm{a}}=89 \mathrm{MPa}$, and $N_{\mathrm{f}}=1.8 \times 10^{5}$; (C) surface-without-RA, $R=0.4, \sigma_{\mathrm{m}}=468 \mathrm{MPa}, \sigma_{\mathrm{a}}=204 \mathrm{MPa}$, and $N_{\mathrm{f}}=2.07 \times 10^{5}$; (D) single-origin interior-with-RA, $R=0.5, \sigma_{\mathrm{m}}=520 \mathrm{MPa}, \sigma_{\mathrm{a}}=159 \mathrm{MPa}$, and $N_{\mathrm{f}}=1.23 \times 10^{8}$; (E) multi-origin interior-with-RA, $R=0.6, \sigma_{\mathrm{m}}=728 \mathrm{MPa}, \sigma_{\mathrm{a}}=204 \mathrm{MPa}$, and $N_{\mathrm{f}}=2.03 \times 10^{7}$; (F) mix-type of surface-withRA and interior-with-RA, $R=0.5, \sigma_{\mathrm{m}}=478 \mathrm{MPa}, \sigma_{\mathrm{a}}=159 \mathrm{MPa}$, and $N_{\mathrm{f}}=7.87 \times 10^{8}$. RA, rough area [Colour figure can be viewed at wileyonlinelibrary.com]

surface-with-RA and surface-without-RA are abbreviated as "surface" or "sur," and the type of interior-with-RA is abbreviated as "interior" or "int."

RA region is regarded as the characteristic area of crack initiation and early growth for the internal crackinduced VHCF of titanium alloys with $\mathrm{BM}^{25,31}$ For the titanium alloys with EM, the RA region is still a typical fractographic feature not only for the cases of internal crack-induced VHCF but also for those of surface-withRA-induced fatigue failure due to the higher value of $V o l_{\text {equi } \alpha}$. Nanograin formation, as well as microstructure refinement underneath the RA region, was found in the surface crack-induced VHCF of the tested titanium alloy with EM under $R=-1 .{ }^{36}$ Note that our previous proposed NCP model emphasizes the essential effect of the compressive part of alternating stress on the microstructure refinement at the originated crack surfaces. ${ }^{35}$ Therefore, the state of $R$ should be paid much attention to, ie, the cyclic stress with or without compressive component.

Surface defects may possibly induce the fatigue failure of engineering materials and structures. In the failure type of surface-with-RA, fatigue crack initiates from the specimen surface and propagates inward to form an RA region. The type of RA region is shortened as "Sur-RA" for both cases of single-origin surface-with-RA and multi-origin surface-with-RA.
The formation of RA morphology is related to the distribution and the volume fraction of equiaxed $\alpha$ grains. For the cases of internal crack initiation, the crack origin is the coalescence of cleavage facets from equiaxed $\alpha$ grains, which is less affected by the fraction of equiaxed $\alpha$ grains. Thus, Int-RA prevails in both EM- and BM-type titanium alloys. While for the cases of surface crack initiation, the crack origin is resulted from surface defect. Thus, for the cases of $R=-1$, EM-type titanium alloys with large fraction of equiaxed $\alpha$ grains ( $\operatorname{Vol}_{\text {equi } \alpha}>75 \%$ as in this paper) are more possible to induce Sur-RA morphology, and BM-type titanium alloys containing small volume fraction of equiaxed $\alpha$ grains ( $V o l_{\text {equi }}$ $\alpha<30 \%$ ) are less possible to induce Sur-RA morphology.

Figure 6 shows the typical morphologies of Sur-RA regions. It is seen that Sur-RA regions may appear both in negative stress ratio cases, eg, $R=-1$ (Figure 6A,B), and in positive stress ratio cases, eg, $R=0.8$ (Figure $6 \mathrm{C}$, $D$ ), in which Figure 6A,C are within $\mathrm{HCF}$ regime, and Figure 6B,D are within VHCF regime. This implies that Sur-RA region is a distinct feature on the fracture surface regardless of the state of $R$ and failure cycles. For the cases of negative stress ratios, the Sur-RA region exhibits the traces of being pressed or ground appearance resulted from the contacting between the crack surfaces, and with the increase of loading cycles, such traces become more 

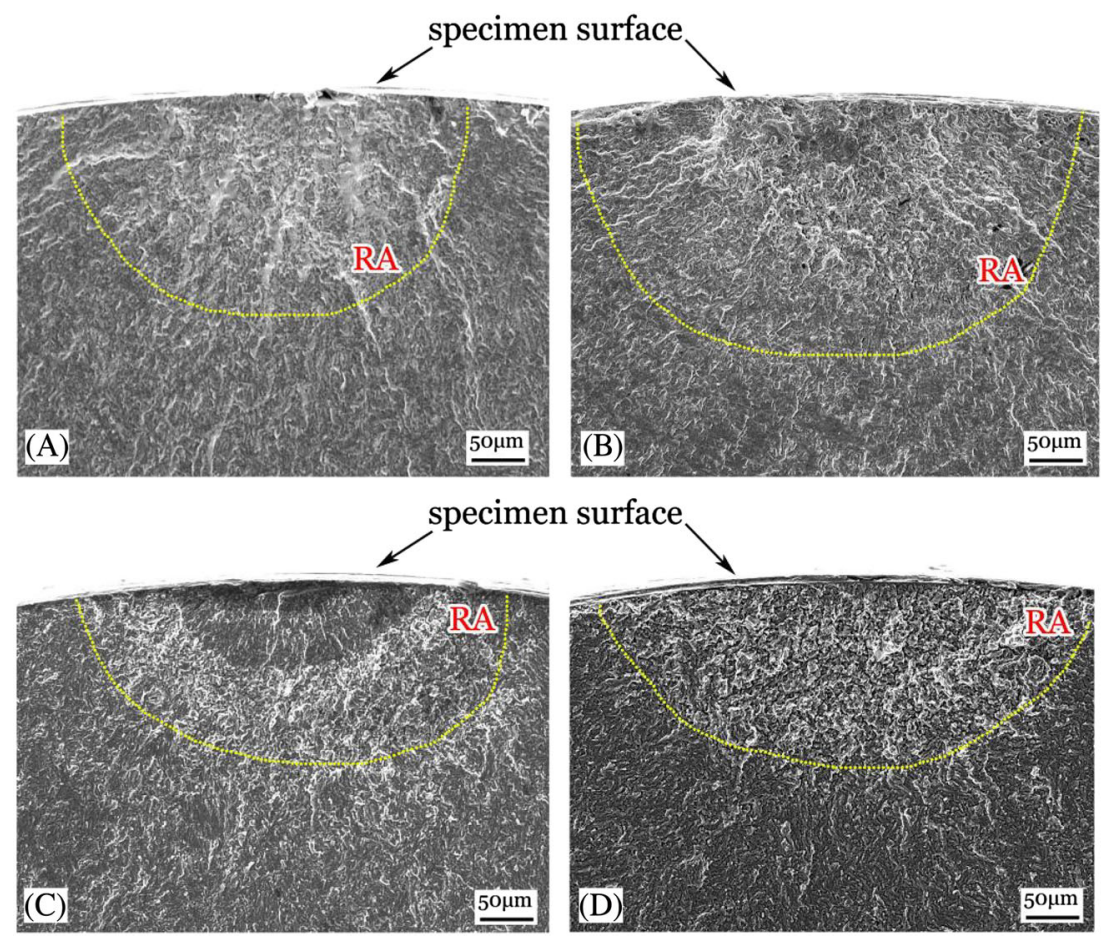

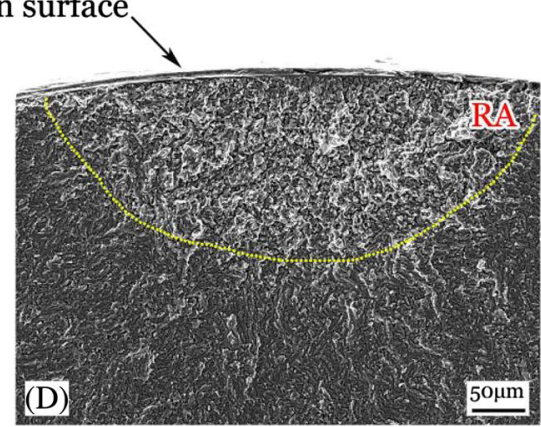

FIGURE 6 Sur-RA morphologies due to different loading conditions: (A)

$R=-1, \sigma_{\mathrm{m}}=0, \sigma_{\mathrm{a}}=533 \mathrm{MPa}$, and $N_{\mathrm{f}}=6.04 \times 10^{5}$; (B) $R=-1, \sigma_{\mathrm{m}}=0$, $\sigma_{\mathrm{a}}=444 \mathrm{MPa}$, and $N_{\mathrm{f}}=1.06 \times 10^{8} ;(\mathrm{C})$ $R=0.8, \sigma_{\mathrm{m}}=784 \mathrm{MPa}, \sigma_{\mathrm{a}}=89 \mathrm{MPa}$, and $N_{\mathrm{f}}=1.8 \times 10^{5}$; (D) $R=0.8, \sigma_{\mathrm{m}}=884 \mathrm{MPa}$, $\sigma_{\mathrm{a}}=113 \mathrm{MPa}$, and $N_{\mathrm{f}}=2.22 \times 10^{7}$. SurRA, crack initiated at specimen surface to form a surface rough area region [Colour figure can be viewed at wileyonlinelibrary. com] evident. For the cases of positive stress ratios, the shape of Sur-RA region gradually transforms from a semicircle to a semi-ellipse.

As the values of $\sigma_{\mathrm{m}}$ and $N_{\mathrm{f}}$ increase, crack origin shifts from specimen surface to the interior and grows to form an RA region. This type of RA region is shortened as "Int-RA" for both cases of single-origin interior-with-RA and multi-origin interior-with-RA.

The typical morphologies of the Int-RA regions are presented in Figure 7. Figure 7A is the case of $R<0$ (exactly $R=-0.3$ ), showing the Int-RA region experienced a VHCF process $\left(\sigma_{\mathrm{m}}=166 \mathrm{MPa}, \sigma_{\mathrm{a}}=293 \mathrm{MPa}\right.$, and $N_{\mathrm{f}}=7.33 \times 10^{7}$ ). Figure 7B is the case of $R>0$ (exactly $R=0.5$ ), showing the Int-RA region experienced a VHCF process $\left(\sigma_{\mathrm{m}}=468 \mathrm{MPa}, \sigma_{\mathrm{a}}=159 \mathrm{MPa}\right.$, and $\left.N_{\mathrm{f}}=4.61 \times 10^{8}\right)$. Figure 7C,D shows the cleavage facets in the Int-RA regions (as indicated by the arrows) under the two loading conditions $(R<0$ and $R>0)$, and the number of facets increases with $R$ from $R<0$ to $R>0$. Figure 7 indicates that Int-RA region is a distinct area on the fracture surface regardless of $N_{\mathrm{f}}$ and $R$ values in VHCF regime. In general, the formation of Int-RA region is in close relation to the existence of cleavage facets, and the Int-RA region always exhibits the feature of a crack with a nearly penny shape. Note that the size of RA region in Figure $7 \mathrm{~B}$ is about twice the size of that in Figure 7A, and the RA size will be discussed in the next section. For the case of $R<0$, there is a visible boundary of ellipse shape tangent to the specimen surface as indicated by the arrows in Figure 7A. For the case of $R>0$, the boundary mark is diminishing.
There is a kind of RA region different from the abovedescribed Sur-RA or Int-RA, which is hardly to be distinguished between surface-with-RA and interior-with-RA from its fracture surface morphology. Thus, this type is named as "Sub-RA."

Figure 8 shows an example of a Sub-RA region that experienced a VHCF process $\left(R=0.1, \sigma_{\mathrm{m}}=312 \mathrm{MPa}\right.$, $\sigma_{\mathrm{a}}=249 \mathrm{MPa}$, and $N_{\mathrm{f}}=1.10 \times 10^{8}$ ). In general, Sub-RA region intersects or is tangent to its specimen surface, which is nearly a penny shape. The same as Int-RA, cleavage facets prevail within Sub-RA region, and the arrow in Figure 8B shows an example. Fatigue striations were observed in the region outside the RA region as indicated by the arrows in Figure $8 \mathrm{C}$. It is apparent that the origin of crack initiation is within the Sub-RA region due to the cleavage facets. That is to say, in the Sub-RA region, the origin of crack initiation is located at specimen subsurface, and gradually the Sub-RA region intersects or is tangent to the specimen surface to become a surface crack leading to final failure of the specimen.

For a better description of RA regions, Figure 9 schematically illustrates the three types of RA regions, namely, Sur-RA, Int-RA, and Sub-RA. The crack initiation is located at the specimen surface for the case of Sur-RA as shown in Figure 9A, and the origin is located in the specimen interior in both Int-RA and Sub-RA as shown in Figure 9B,C. The distance between crack origin, ie, RA centre and specimen surface, is defined as RA depth and denoted as $d_{\mathrm{RA}}$ as shown in Figure 9. Thus, $d_{\mathrm{RA}}=0$ for the case of Sur-RA. 
-

FIGURE 7 Int-RA morphology for different loading conditions: (A) The specimen failed in VHCF regime with $R=-0.3, \sigma_{\mathrm{m}}=166 \mathrm{MPa}, \sigma_{\mathrm{a}}=293 \mathrm{MPa}$, and $N_{\mathrm{f}}=7.33 \times 10^{7}$, the arrows indicating boundary mark; (B) the specimen failed in VHCF regime with $R=0.5$,

$\sigma_{\mathrm{m}}=468 \mathrm{MPa}, \sigma_{\mathrm{a}}=159 \mathrm{MPa}$, and $N_{\mathrm{f}}=4.61 \times 10^{8} ;(\mathrm{C}, \mathrm{D})$ detail for the RA region marked by the box in (A) and (B), the arrows indicating cleavage facets. Int$\mathrm{RA}$, crack initiated at specimen interior to form an internal RA region; RA, rough area; VHCF, very-high-cycle fatigue [Colour figure can be viewed at wileyonlinelibrary.com]

FIGURE 8 (A) An SEM image showing Sub-RA morphology, $R=0.1$, $\sigma_{\mathrm{m}}=312 \mathrm{MPa}, \sigma_{\mathrm{a}}=249 \mathrm{MPa}$, and $N_{\mathrm{f}}=1.10 \times 10^{8}$; (B) enlargement of the RA region marked by the box in (A) and the arrow indicating a cleavage facet; and (C) enlargement of a region outside RA region and the arrows indicating fatigue striations. RA, rough area; SEM, scanning electron microscope; Sub-RA, crack initiated at subsurface to form a surface RA region [Colour figure can be viewed at wileyonlinelibrary.com]
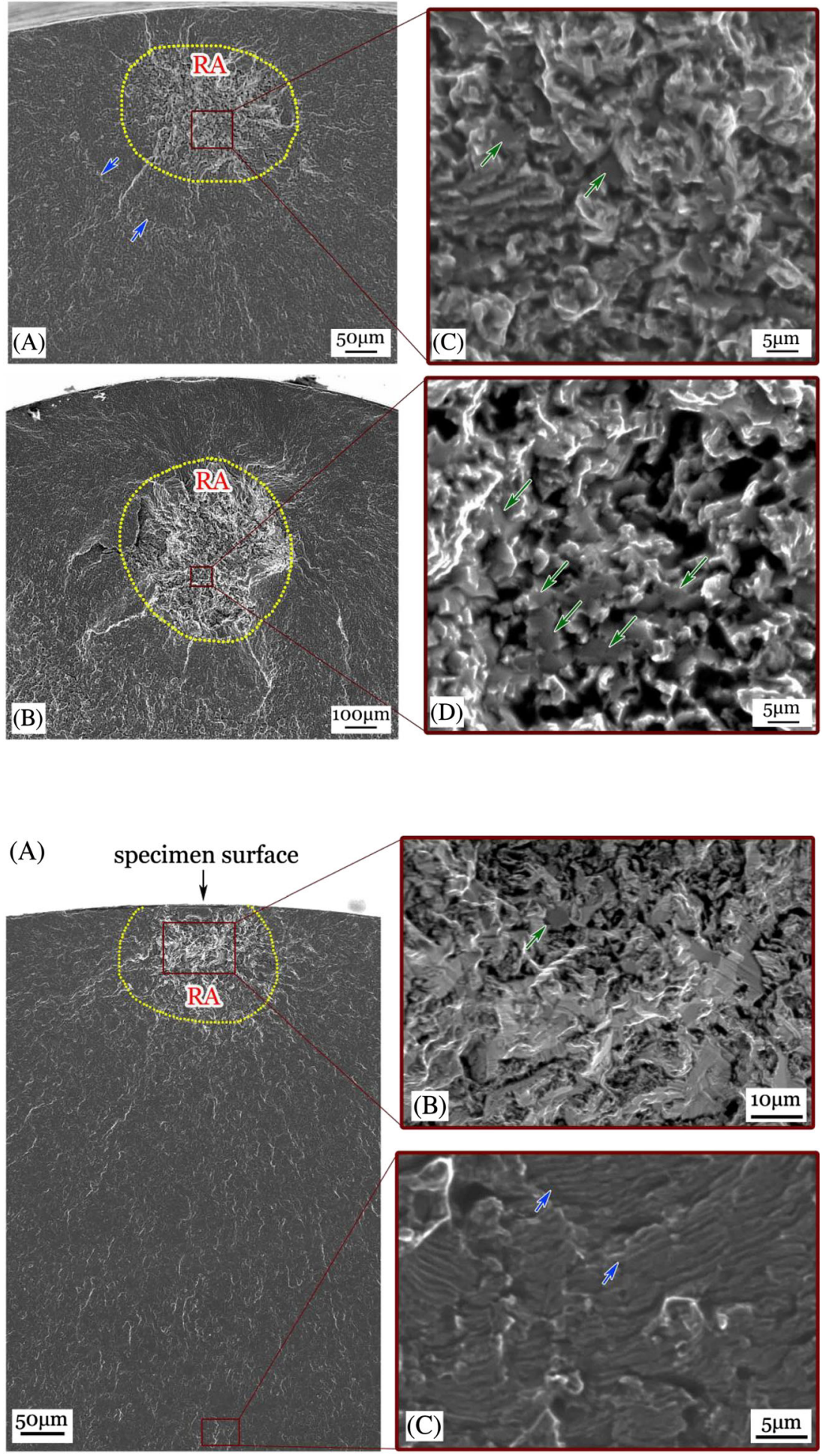

\section{3 | $K_{\max }$ and $\Delta K$ for $\mathrm{RA}$ regions}

Figure 10 shows the values of the size and its distribution for the observed RA regions, in which Figure 10A,B shows the size of RA regions as a function of $\sigma_{\mathrm{a}}$ and $N_{\mathrm{f}}$, and Figure 10C shows the values of $d_{\mathrm{RA}}$ as a function of $N_{\mathrm{f}}$. It is seen that the size of RA regions increases with the decrease of $\sigma_{\mathrm{a}}$, but there seems not a clear variation trend between the RA size and $N_{\mathrm{f}}$. For the distribution of RA depth from specimen surface, it is obvious that $d_{\mathrm{RA}}$ beyond zero only occurs in VHCF regime, and no evident correlation between the depth and $N_{\mathrm{f}}$ occurs.

The parameter of SIF $K$ is often used to describe fatigue crack growth. For considering the effect of crack 


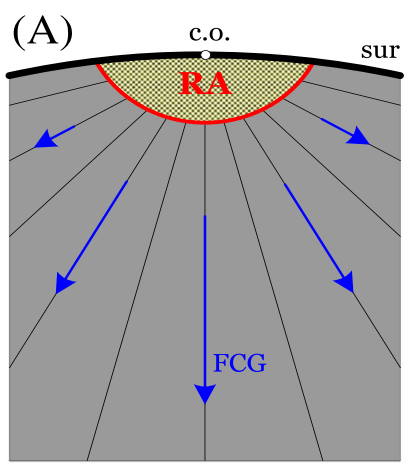

(B)

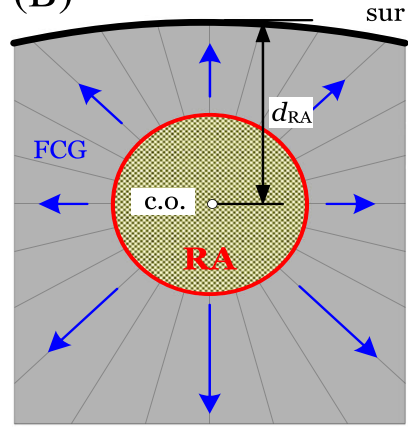

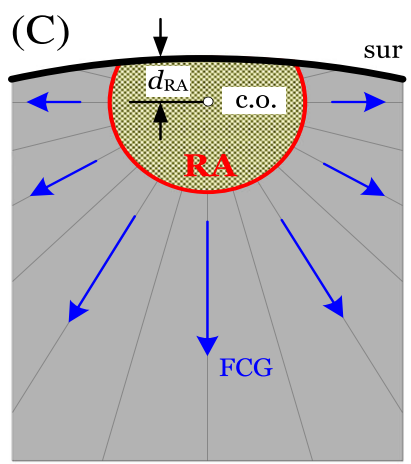

FIGURE 9 Schematic illustration of RA regions in fracture surface: (A) Sur-RA, (B) Int-RA, and (C) Sub-RA. c.o., crack origin, ie, RA centre; FCG, fatigue crack growth; Int-RA, crack initiated at specimen interior to form an internal RA region; RA, rough area; Sub-RA, crack initiated at subsurface to form a surface RA region; sur, specimen surface; Sur-RA, crack initiated at sur to form a surface RA region [Colour figure can be viewed at wileyonlinelibrary.com]

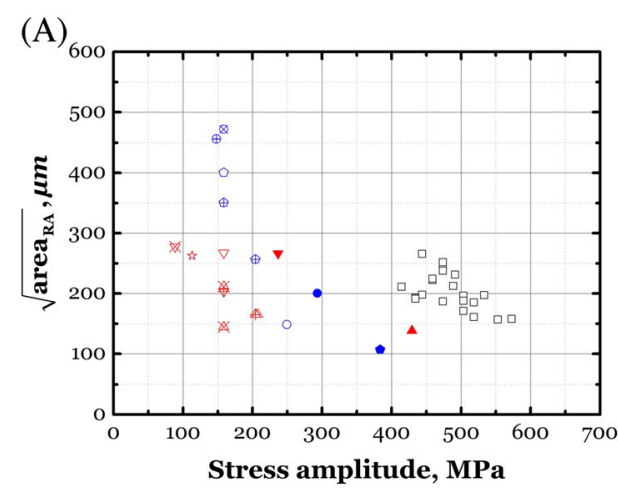

Stress amplitude, MPa

(C)

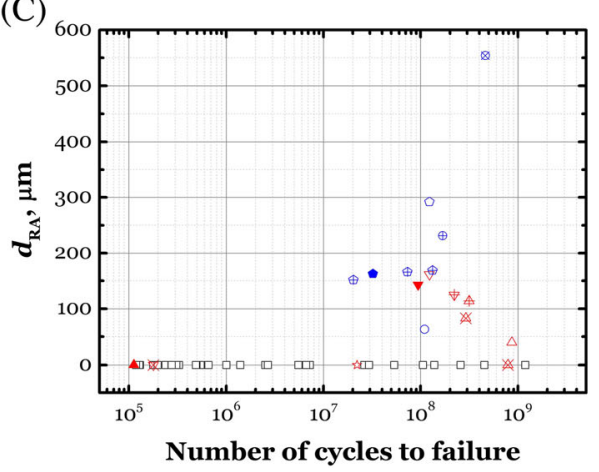

(B)

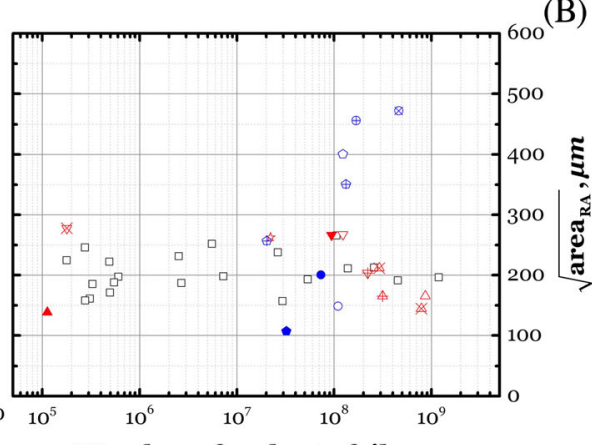

Number of cycles to failure

\begin{tabular}{|c|c|c|c|}
\hline \multicolumn{4}{|c|}{$R<0$} \\
\hline$\sigma_{\mathrm{m}}$ & sur & int & $R$ \\
\hline & 口 & & -1 \\
\hline 166MPa: & & - & -0.3 \\
\hline 208MPa: & $\Delta$ & - & -0.3 \\
\hline 220MPa: & $\checkmark$ & & 0 \\
\hline \multicolumn{4}{|c|}{$R>0$} \\
\hline$\sigma_{\mathrm{m}}$ & sur & int & $R$ \\
\hline 220MPa: & $\Delta$ & & 0 \\
\hline 312MPa: & A & 0 & 0.20 .1 \\
\hline 447MPa: & & $\oplus$ & 0.5 \\
\hline 468MPa: & $\not x$ & $\otimes$ & 0.5 \\
\hline 520MPa: & $\nabla$ & 0 & 0.5 \\
\hline $728 \mathrm{MPa}:$ & $\forall$ & $\oplus$ & 0.6 \\
\hline $784 \mathrm{MPa}:$ & $\not x$ & & 0.8 \\
\hline 884MPa: & $\Rightarrow$ & & 0.8 \\
\hline
\end{tabular}

FIGURE 10 Results of RA size and RA depth under different values of $\sigma_{\mathrm{m}}$. A, RA size versus $\sigma_{\mathrm{a}}$; B, RA size versus $N_{\mathrm{f}}$; and C, RA depth versus $N_{\mathrm{f}}$ RA, rough area [Colour figure can be viewed at wileyonlinelibrary.com]

closure, the concept of effective stress is usually adopted. For the case of $R<0$, the maximum value of SIF $K_{\max }$ dominates the behaviour of fatigue crack growth, whereas for the case of $R>0$, the range of SIF $\Delta K$ becomes dominant.

The values of $K_{\max }$ and $\Delta K$ for the RA regions were calculated by Equations (4) and (5), which are with regard to the formulae proposed by Murakami et al. ${ }^{47}$

$$
K_{\max }=C \sigma_{\max } \sqrt{\pi \sqrt{\operatorname{area}_{\mathrm{RA}}}}
$$

$$
\Delta K=2 C \sigma_{\mathrm{a}} \sqrt{\pi \sqrt{\operatorname{area}_{\mathrm{RA}}}}
$$

where $C=0.5$ for internal crack and $C=0.65$ for surface crack. The results are presented in Figure 11.

As shown in Figure 11A, the values of $K_{\max }$ or $\Delta K$ at the periphery of internal RA regions almost converge to a constant regardless of $N_{\mathrm{f}}$ in VHCF regime. For the case of $R<0, K_{\max }=5.59 \mathrm{MPa} \cdot \mathrm{m}^{1 / 2}$; and for the case of $R>0$, $\Delta K=5.63 \mathrm{MPa} \cdot \mathrm{m}^{1 / 2}$. Whereas for the surface case of $\sigma_{\mathrm{m}}=0$, ie, $R=-1, K_{\max }=7.74 \mathrm{MPa} \cdot \mathrm{m}^{1 / 2}$ in VHCF regime, which is still near a constant regardless of $N_{\mathrm{f}}$ with 


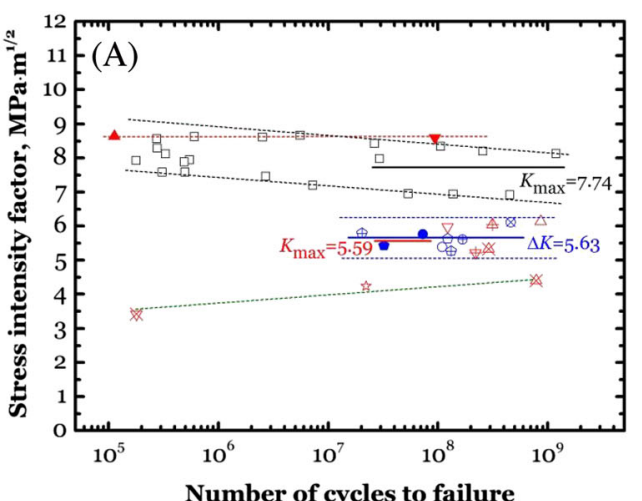

Number of cycles to failure

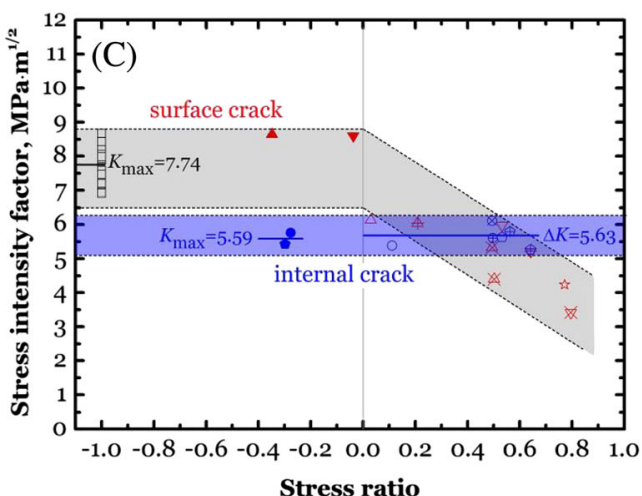

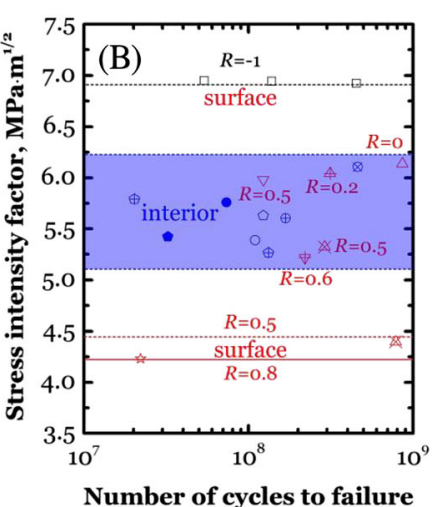

\begin{tabular}{|c|c|c|c|}
\hline \multicolumn{4}{|c|}{$R<0, K \max$} \\
\hline$\sigma_{\mathrm{m}}$ & sur & int & $R$ \\
\hline o: & 口 & & -1 \\
\hline 166MPa: & & - & -0.3 \\
\hline 208MPa: & $\Delta$ & - & -0.3 \\
\hline 220MPa: & $\nabla$ & & 0 \\
\hline \multicolumn{4}{|c|}{$R>0, \Delta K$} \\
\hline$\sigma_{\mathrm{m}}$ & sur & int & $R$ \\
\hline 220MPa: & $\Delta$ & & 0 \\
\hline 312MPa: & 4 & 0 & $\begin{array}{ll}0.2 & 0.1\end{array}$ \\
\hline $447 \mathrm{MPa}:$ & & $\oplus$ & 0.5 \\
\hline 468MPa: & 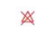 & $\otimes$ & 0.5 \\
\hline 520MPa: & $\nabla$ & 0 & 0.5 \\
\hline 728MPa: & $\forall$ & $\oplus$ & 0.6 \\
\hline $784 \mathrm{MPa}:$ & $\not x$ & & 0.8 \\
\hline 884MPa: & if & & 0.8 \\
\hline
\end{tabular}

FIGURE 11 Correlation of stress intensity factor at the periphery of RA regions with $N_{\mathrm{f}}$ and $R$ for the specimens under different values of $\sigma_{\mathrm{m}}$. (A) Stress intensity factor versus $N_{\mathrm{f}}$, (B) enlargement of a part in (A), and (C) stress intensity factor versus $R$. RA, rough area [Colour figure can be viewed at wileyonlinelibrary. com]

\section{4 | Microstructure feature of RA regions}

Figure 12 shows TEM observations of the fracture surface profile for the three typical RA regions in VHCF regime: Sur-RA at $R=-1$, Sub-RA at $R=0$, and Int-RA at $R=0.5$. Figure 12A-D presents the locations for FIB milling to prepare the TEM samples in the RA regions as indicated by the red bars. Figure 12E-H shows the BF images of the TEM samples showing the microstructure morphologies underneath the selected positions in the RA regions. Figure 12I-P shows the SAD patterns for the circular domains in Figure 12E-H, with the diameter of $200 \mathrm{~nm}$ for each. Note that the two SAD patterns of each RA region in Figure 12 are representative results from about $10 \mathrm{SAD}$ detections at each TEM sample.

It is seen from Figure 12E,F that the microstructure in Sur-RA region is refined, and the thickness of this refined layer is several hundred nanometres. The SAD pattern underneath the Sur-RA region (Figure 12I,L) is discontinuous diffraction rings, and the SAD pattern away from the Sur-RA region (Figure 12J,K) is regular isolated diffraction spots, suggesting that the microstructure underneath the fracture surface of Sur-RA region for the VHCF cases of $R=-1$ is a nanograin layer of several hundred nanometres thick. For the cases of $R=0$ (Figure 12C) and $R=0.5$ (Figure 12D), the decreases as $R$ increases. 

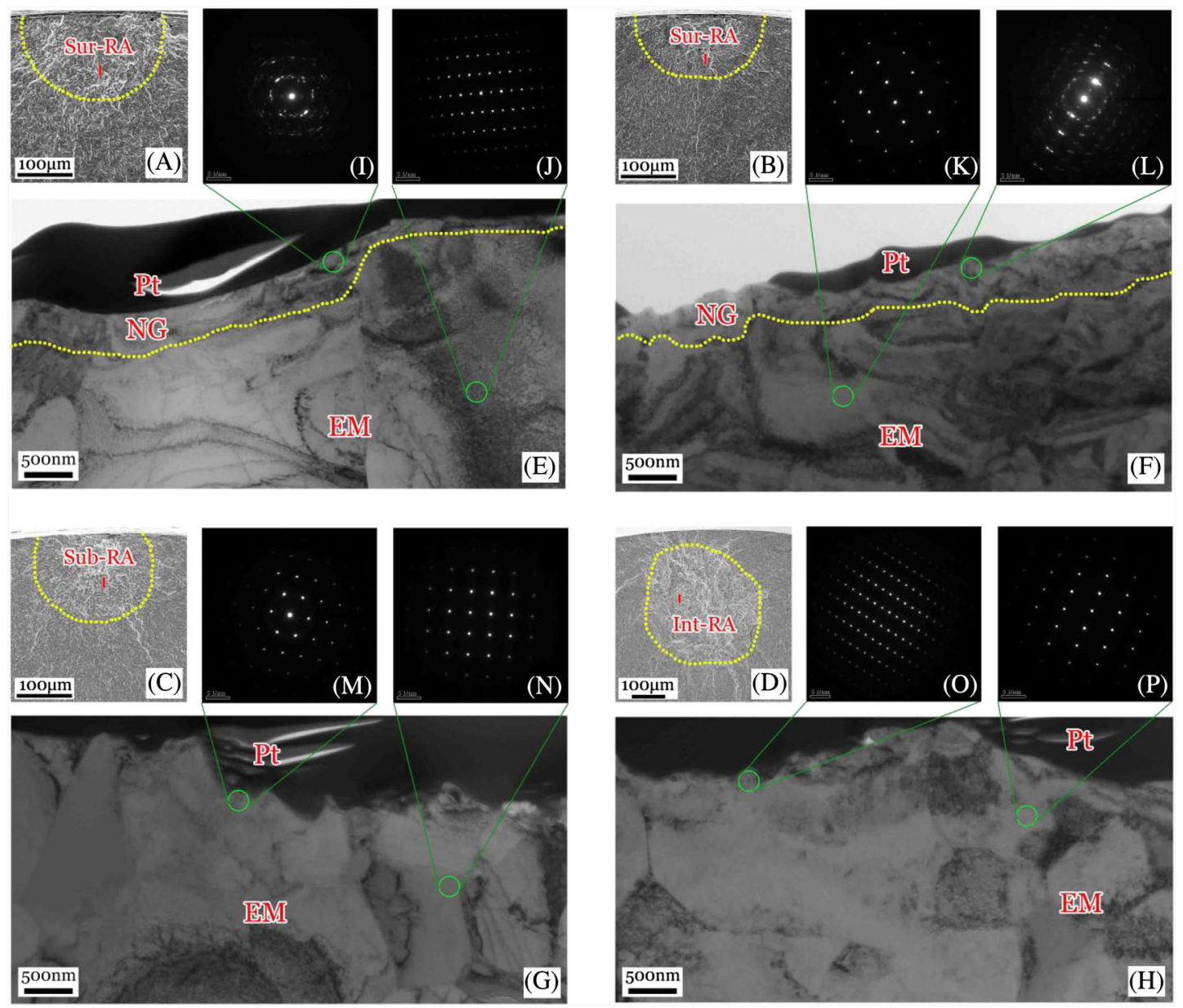

FIGURE 12 Microstructure characterization for the rough area (RA) regions in very-high-cycle fatigue (VHCF): (A) Sur-RA, $R=-1$, $\sigma_{\mathrm{m}}=0, \sigma_{\mathrm{a}}=444 \mathrm{MPa}$, and $N_{\mathrm{f}}=1.058 \times 10^{8}$; (B) Sur-RA, $R=-1, \sigma_{\mathrm{m}}=0, \sigma_{\mathrm{a}}=434 \mathrm{MPa}$, and $N_{\mathrm{f}}=4.507 \times 10^{8}$; (C) Sub-RA, $R=0$, $\sigma_{\mathrm{m}}=220 \mathrm{MPa}, \sigma_{\mathrm{a}}=207 \mathrm{MPa}$, and $N_{\mathrm{f}}=8.633 \times 10^{8}$; (D) Int-RA, $R=0.5, \sigma_{\mathrm{m}}=440 \mathrm{MPa}, \sigma_{\mathrm{a}}=148 \mathrm{MPa}$, and $N_{\mathrm{f}}=1.679 \times 10^{8}$. Red bars in $(\mathrm{A})$ to (D) denoting focused ion beam (FIB) positioning locations of transmission electron microscopy (TEM) samples. (E-H) Bright field (BF) images for the FIB samples in (A-D), respectively. Pt, platinum protection layer; NG, nanograin layer; EM, original equiaxed microstructure. (I-P) Selected area diffraction (SAD) patterns for the circular domains in (E-H). Int-RA, crack initiated at specimen interior to form an internal RA region; Sub-RA, crack initiated at subsurface to form a surface RA region; Sur-RA, crack initiated at specimen surface to form a surface RA region [Colour figure can be viewed at wileyonlinelibrary.com]

microstructure of Sub-RA region (Figure 12G) or Int-RA region (Figure $12 \mathrm{H}$ ) is without the evidence of microstructure refinement, and the SAD pattern either just underneath or away from the RA region (Figure 12M-P) is clearly isolated diffraction spots, suggesting a single grain for the detected area. This result is a new example of the nanograin layer in the crack initiation region under negative $R$ in VHCF regime for the titanium alloy with EM, which supports our proposed NCP model of nanograin formation in the crack initiation region under negative $R$ conditions in VHCF regimes, ${ }^{35}$ for which the nanograin formation resulted from the contacting between the originated crack surfaces assisted by the effects of crack closure and the relaxation of residual stress.
At the end, it is of interest to clarify what are the same and what are the different characteristics between RA in titanium alloys and FGA in high-strength steels. Basically, either RA or FGA is the characteristic region of internal crack initiation, ${ }^{6,25,30,35}$ for which the value of $\Delta K_{\mathrm{RA}}$ or $\Delta K_{\mathrm{FGA}}$ keeps almost constant with its value close to the relevant threshold for long crack growth, and the region of RA or FGA consumes a majority part of total fatigue life. For negative $R$ cases, the region of RA or FGA is a nanograin layer, which is explained by the NCP mechanism. ${ }^{6,31,35}$ It should be emphasized that the region of RA in titanium alloys is produced by the coalescence of cleaved $\alpha$ grains, and for the cases of $R>0$, RA consists of clear cleavage facets without evidence of grain refinement, whereas the region of 
FGA in high-strength steels is produced by the contacting between crack surfaces surrounding the crack origin of an inclusion or other inhomogeneity for negative $R$ cases. In addition, the size of RA in titanium alloys is about several hundred microns, which is obviously larger than that of FGA in high-strength steels, with the size being about tens of microns, and the roughness of RA is about several microns, which is evidently larger than that of FGA with the roughness being around one micron or less. ${ }^{6}$

\section{4 | CONCLUSIONS}

This paper experimentally investigates the $\mathrm{HCF}$ and the VHCF behaviour of a titanium alloy (Ti-6Al-4V) with EM under different mean stresses $\left(\sigma_{\mathrm{m}}\right.$ between 0 and $884 \mathrm{MPa})$ and stress ratios ( $R$ between -1 and 0.8$)$ with the fatigue failure cycles between $10^{5}$ and $2 \times 10^{9}$ via ultrasonic axial cycling. The main conclusions are as follows:

1. The effects of mean stress or stress ratio on HCF and VHCF performance for the titanium alloy were described by Haigh diagrams. The variation of fatigue resistance with fatigue life is affected by both mean stress and stress ratio. Goodman relation has a relatively good fit in HCF regime, and our proposed formula can describe the fatigue performance in VHCF regime under different mean stresses or stress ratios.

2. RA region is a characteristic area of crack initiation for HCF and VHCF of the titanium alloy with EM, which is classified as Sur-RA, Int-RA, and Sub-RA. The crack origin of Sur-RA initiated from specimen surface then formed a surface crack, which occurred in $\mathrm{HCF}$ and $\mathrm{VHCF}$ regimes regardless of stress ratio. The crack origin of Int-RA initiated from specimen interior then formed an internal crack, and the crack origin of Sub-RA initiated from specimen subsurface then formed a surface crack. Both Int-RA and Sub-RA occurred in VHCF regime under tensile mean stress.

3. For internal crack initiation cases, the value of $K_{\max }$ or $\Delta K$ for the RA regions keeps constant regardless of $R$. For surface crack initiation cases, when $R<0$, the value of $K_{\max }$ for the RA regions keeps constant, but when $R>0$, the value of $\Delta K$ for the RA regions decreases with the increase of $R$ value. This is the typical propensity reflecting the variation of the resultant $K_{\max }$ or $\Delta K$ of the related RA region with $R$ for internal crack initiation and surface crack initiation modes.
4. The mechanism of NCP dominates the microstructure evolution of the characteristic region of crack initiation (RA region) in the titanium alloy with EM. Even for the cases of Sur-RA and Sub-RA, nanograin formation in the crack initiation region occurred only in the specimens experienced VHCF process under negative stress ratio.

\section{ACKNOWLEDGEMENTS}

The authors would like to thank the financial support from the National Natural Science Foundation of China (11572325) and from the Strategic Priority Research Program of the Chinese Academy of Sciences (XDB22040503 and XDB22020201).

\section{ORCID}

Xiangnan Pan (1) https://orcid.org/0000-0001-7794-725X

Youshi Hong (DD https://orcid.org/0000-0003-3425-6808

\section{REFERENCES}

1. Suresh S. Fatigue of Materials. 2nd ed. Cambridge: Cambridge University Press; 1998.

2. Naito T, Ueda H, Kikuchi M. Observation of fatigue fracture surface of carburized steel. J Soc Mater Sci. 1983;32(361): $1162-1166$

3. Mughrabi H. On multi-stage fatigue life diagrams and the relevant life-controlling mechanisms in ultrahigh-cycle fatigue. Fatigue Fract Eng Mater Struct. 2002;25(8-9):755-764.

4. Zimmermann M. Diversity of damage evolution during cyclic loading at very high numbers of cycles. Int Mater Rev. 2012;57(2):73-91.

5. Mayer H. Recent developments in ultrasonic fatigue. Fatigue Fract Eng Mater Struct. 2016;39(1):3-29.

6. Hong Y, Sun C. The nature and the mechanism of crack initiation and early growth for very-high-cycle fatigue of metallic materials-an overview. Theor Appl Fract Mech. 2017; 92:331-350.

7. Liu H, He C, Huang Z, Wang Q. Very high cycle fatigue failure mechanism of TC17 alloy. Acta Metall Sin. 2017;53(9): 1047-1054

8. Jeddi D, Palin-Luc T. A review about the effects of structural and operational factors on the gigacycle fatigue of steels. Fatigue Fract Eng Mater Struct. 2018;41(5):969-990.

9. Tridello A, Biffi C, Fiocchi J, et al. VHCF response of as-built SLM AlSi10Mg specimens with large loaded volume. Fatigue Fract Eng Mater Struct. 2018;41(9):1918-1928.

10. Neal F, Blenkinsop P. Internal fatigue origins in $\alpha-\beta$ titanium alloys. Acta Metall. 1976;24(1):59-63. 
11. Chandran K. Duality of fatigue failures of materials caused by Poisson defect statistics of competing failure modes. Nat Mater. 2005;4(4):303-308.

12. Chandran K, Jha S. Duality of the S-N fatigue curve caused by competing failure modes in a titanium alloy and the role of Poisson defect statistics. Acta Mater. 2005;53(7):1867-1881.

13. Atrens A, Hoffelner W, Duerig T, Allison J. Subsurface crack initiation in high cycle fatigue in Ti-6Al-4V and in a typical martensitic stainless steel. Scripta Metall. 1983;17(5):601-606.

14. Takeuchi E, Furuya Y, Nagashima N, Matsuoka S. The effect of frequency on the giga-cycle fatigue properties of a Ti-6Al-4V alloy. Fatigue Fract Eng Mater Struct. 2008;31(7):599-605.

15. Oguma $H$, Nakamura $T$. The effect of microstructure on very high cycle fatigue properties in Ti-6Al-4V. Scripta Mater. 2010;63(1):32-34.

16. Heinz S, Balle F, Wagner G, Eifler D. Analysis of fatigue properties and failure mechanisms of Ti6Al4V in the very high cycle fatigue regime using ultrasonic technology and 3D laser scanning vibrometry. Ultrasonics. 2013;53(8):1433-1440.

17. Heinz S, Eifler D. Crack initiation mechanisms of Ti6Al4V in the very high cycle fatigue regime. Int J Fatigue. 2016;93: 301-308.

18. Cao F, Chandran K. The role of crack origin size and early stage crack growth on high cycle fatigue of powder metallurgy Ti-6Al4V alloy. Int J Fatigue. 2017;102:48-58.

19. Zheng Y, Zhao Z, Zhang Z, Zong W, Dong C. Internal crack initiation characteristics and early growth behaviors for very highcycle fatigue of a titanium alloy electron beam welded joints. Mater Sci Eng A. 2017;706:311-318.

20. Uematsu Y, Kakiuchi T, Hattori K. EBSD-assisted fractography of sub-surface fatigue crack initiation mechanism in the ultrasonic-shot-peened ßeta-type titanium alloy. Fatigue Fract Eng Mater Struct. 2018;41(11):2239-2248.

21. Gerber H. Bestimmung der zulässigen spannungen in eisenkonstructionen. Zeitschrift des Bayerischen Architeckten und Ingenieur-Vereins. 1874;6(6):101-110.

22. Goodman J. Mechanics Applied to Engineering. London: Longmans Green; 1899.

23. Sakai T, Sato Y, Nagano Y, Takeda M, Oguma N. Effect of stress ratio on long life fatigue behavior of high carbon chromium bearing steel under axial loading. Int J Fatigue. 2006;28(11): 1547-1554.

24. Huang Z, Liu H, Wang H, Wagner D, Khan M, Wang Q. Effect of stress ratio on VHCF behavior for a compressor blade titanium alloy. Int J Fatigue. 2016;93:232-237.

25. Liu X, Sun C, Hong Y. Effects of stress ratio on high-cycle and very-high-cycle fatigue behavior of a Ti-6Al-4V alloy. Mater Sci Eng a. 2015;622:228-235.

26. Liu X, Sun C, Hong Y. Faceted crack initiation characteristics for high-cycle and very-high-cycle fatigue of a titanium alloy under different stress ratios. Int J Fatigue. 2016;92:434-441.

27. Liu X, Sun C, Zhou Y, Hong Y. Effects of microstructure and stress ratio on high-cycle and very-high-cycle fatigue behavior of Ti-6Al-4V alloy. Acta Metall Sin. 2016;52(8):923-930.
28. Furuya Y, Takeuchi E. Gigacycle fatigue properties of Ti-6Al-4V alloy under tensile mean stress. Mater Sci Eng a. 2014;598:135-140.

29. Nikitin A, Palin-Luc T, Shanyavskiy A. Crack initiation in VHCF regime on forged titanium alloy under tensile and torsion loading modes. Int J Fatigue. 2016;93:318-325.

30. Hong Y, Lei Z, Sun C, Zhao A. Propensities of crack interior initiation and early growth for very-high-cycle fatigue of high strength steels. Int J Fatigue. 2014;58:144-151.

31. Su H, Liu X, Sun C, Hong Y. Nanograin layer formation at crack initiation region for very-high-cycle fatigue of a Ti-6Al-4V alloy. Fatigue Fract Eng Mater Struct. 2017;40(6):979-993.

32. Sakai T, Takeda M, Shiozawa K, et al. Experimental reconfirmation of characteristic S-N property for high carbon chromium bearing steel in wide life region in rotating bending. $J$ Soc Mater Sci. 2000;49(7):779-785.

33. Zhao A, Xie J, Sun C, Lei Z, Hong Y. Prediction of threshold value for FGA formation. Mater Sci Eng a. 2011;528(2223):6872-6877.

34. Zhao A, Xie J, Sun C, Lei Z, Hong Y. Effects of strength level and loading frequency on very-high-cycle fatigue behavior for a bearing steel. Int J Fatigue. 2012;38:46-56.

35. Hong Y, Liu X, Lei Z, Sun C. The formation mechanism of characteristic region at crack initiation for very-high-cycle fatigue of high-strength steels. Int J Fatigue. 2016;89:108-118.

36. Pan X, Su H, Sun C, Hong Y. The behavior of crack initiation and early growth in high-cycle and very-high-cycle fatigue regimes for a titanium alloy. Int J Fatigue. 2018;115:67-78.

37. Ritz F, Stäcker C, Beck T, Sander M. FGA formation mechanism for X10CrNiMoV12-2-2 and 34CrNiMo6 for constant and variable amplitude tests under the influence of applied mean loads. Fatigue Fract Eng Mater Struct. 2018;41(7): 1576-1587.

38. Stanzl-Tschegg S, Schönbauer B. Near-threshold fatigue crack propagation and internal cracks in steel. Procedia Engineering. 2010;2(1):1547-1555.

39. Hu Y, Sun C, Hong Y. Crack growth rates and microstructure feature of initiation region for very-high-cycle fatigue of a high-strength steel. Fatigue Fract Eng Mater Struct. 2018;41(8):1717-1732.

40. Ogawa T, Stanzl-Tschegg SE, Schoenbauer BM. A fracture mechanics approach to interior fatigue crack growth in the very high cycle regime. Eng Fract Mech. 2014;115:241-254.

41. Sander M, Muller T, Stacker C. Very high cycle fatigue behavior under constant and variable amplitude loading. Procedia Struct Inte. 2016;2:34-41.

42. Petit J, Sarrazin-Baudoux C. An overview on the influence of the atmosphere environment on ultra-high-cycle fatigue and ultraslow fatigue crack propagation. Int J Fatigue. 2006;28(11): 1471-1478.

43. Sadananda K, Vasudevan A. Fatigue crack growth behavior of titanium alloys. Int J Fatigue. 2005;27(10-12):1255-1266.

44. Oguma H, Nakamura T. Fatigue crack propagation properties of Ti-6Al-4V in vacuum environments. Int J Fatigue. 2013;50: 89-93. 
45. Bathias C, Paris P. Gigacycle fatigue in mechanical practice. New York: Marcel Dekker; 2005.

46. Sendeckyj G. Constant life diagrams-a historical review. Int $J$ Fatigue. 2001;23(4):347-353.

47. Murakami Y, Kodama S, Konuma S. Quantitative evaluation of effects of non-metallic inclusions on fatigue strength of high strength steels. Int J Fatigue. 1989;11(5):291-298.
How to cite this article: Pan X, Hong Y. Highcycle and very-high-cycle fatigue behaviour of a titanium alloy with equiaxed microstructure under different mean stresses. Fatigue Fract Eng Mater Struct. 2019;1-15. https://doi.org/10.1111/ffe.13050 